\title{
Legislative hazard: keeping patients living, against their wills
}

\author{
Lawrence L Heintz University of Hawaii at Hilo
}

\section{Author's abstract}

Natural death act legislation which is intended to assist patients who wish to refuse or limit medical treatment may actually erode patients' rights. By use of a 'living will' the legislation intends to extend the patients' role in decisionmaking to the time when patients can no longer speak for themselves. However, the legislation erodes and constricts the right of refusal. The erosion is the result of two sets of conditions found in the legislation. The first requires that the patient be qualified and certified by others before interventions can be withdrawn or withheld. The second delineates the physical condition which must be present before a living will can be followed. Patients have had to seek the assistance of the courts to enforce their common law rights of refusal of treatment against these requirements. Legislation is needed, but greater care must be taken to avoid the creation of a Kafkaesque legal nightmare for those we intend to assist.

\section{Introduction}

On June 13, 1986 the Governor of Hawaii signed a Bill relating to 'medical treatment decisions' and thereby added Hawaii to the thirty-six States which have seen the need for what has come to be known as 'right to die legislation'. This year eight States in addition to Hawaii considered legislation extensively modelled on the 1976 'California Natural Death Act', the first legislation of this kind. Common features of such legislation are that it provides legal status for 'living wills', rejects all forms of euthanasia, and provides a legal umbrella for those respecting the wishes of patients who refuse life-sustaining medical interventions. The difficulty is that concomitantly and unwittingly most of this legislation jeopardises the patient's right to refuse treatment.

The term 'living will' was introduced in 1967 to refer to a document drawn up by a person of sound mind which serves as a testament of his/her wishes regarding the use of life-sustaining medical interventions. The topic evokes strong reactions from both supporters and

\section{Key words}

Living wills; Natural Death Acts; refusal of treatment; autonomy; legislative paternalism. detractors of the so called 'right to die' legislation. Objections to legislative action persist despite the fact that the vast majority of people have little difficulty completing the statement: "If I were in the following condition(s) --.---.-.- I would not want my life sustained by artificial means'. Legislation which addresses concerns about the decision-making that goes on during the last days, weeks, months, and even years of the lives of patients who have lost the ability to participate in those decisions, has produced controversy and a struggle in every State of the Union. My study leads me to urge caution because such legislation is easily misunderstood and often brings unexpected consequences. A poorly drafted natural death act can lead to erosion of patient rights rather than fulfilment of patient wishes.

My objection is not to 'living wills' or 'durable powers of attorney for health care decisions', but to two fatal flaws that have found their way into most legislation in this area of health care. I will attempt to demonstrate that nearly all present legislation on this topic suffers from one, if not both flaws. A discussion of relevant sections of statutes in California, Washington, Idaho, and Hawaii should be ample to reveal the condition of most legislation. I select California because its legislation has served as a model for most legislation; Washington and Idaho represent early and representative statutes, and Hawaii's law is amongst the most recent generation of such legislation which attempts to avoid the pitfalls of its predecessors.

\section{The first flaw: qualification and certification of patients}

In many respects the Hawaii statute is modelled on the California law which is generating considerable litigation due to a provision which requires 'certification of patients as qualified' in order to have their living wills followed (1). The approach of 'qualifying and certifying' patients is counter to: common law rights of patients; fundamental principles of medical ethics; case law in several States, and federal and State constitutional protections.

The right to refuse treatment is found in three traditions: philosophical individualism, the common law right of self-determination, and the constitutionally protected right of privacy. In the 1891 
case of Union Pacific Railway Co $v$ Botsford the United States Supreme Court recognised a patient's right to refuse consent to treatment (2). The court stated: 'No right is held more sacred or is more carefully guarded by the common law than the right of every individual to the possession and control of his own person, free from all restraints or interference by others, unless by clear and unquestionable authority of law'. The more specific principle of patient autonomy is affirmed in the legal right of self-determination in American law, see Schloendorff $v$ Society of New York Hospitals (3). In that case Justice Cardozo wrote: 'Every human being of adult years and of sound mind has a right to determine what shall be done with his body'.

The moral tradition of medical ethics and our legal system recognise patients' rights to control their bodies and patients' rights to be protected from unwanted intrusions or 'unconsented touchings'. The patientphysician relationship is a fiduciary one in which the patient's withdrawal or refusal of consent is decisive. The patient's right of refusal is fundamental and unrestricted. Patients do not need to be 'qualified' or 'certified', they need only be mentally competent to refuse treatment. The important judicial opinion expressed in Natanson $v$ Kline is quite explicit on this matter. 'Anglo-American law starts with the premise of thorough-going self-determination. It follows that each man is considered to be master of his own body, and he may, if he be of sound mind, prohibit the performance of life-saving surgery or other medical treatment' (4).

Three recent California cases reveal further aspects of the dangers to patients' rights presented by legislation which requires that patients be certified as qualified to refuse treatment or to have existing treatments withdrawn. The Federal District Court in Foster $v$ Tourtellotte held that a competent and informed request by a patient for the discontinuance of a respirator was to be respected despite the fact that the patient did not meet the 'requirements of the California Natural Death Act' (5). The court held that the continued use of the respirator constituted an invasion of his 'constitutional rights of self-dignity, privacy and liberty as guaranteed by the penumbra of specific guarantees of the Bill of Rights and more specifically the Fifth Amendment of the United States Constitution'. The order to remove the respirator was appealed but the patient died before the appeal was heard. In the Bartling $v$ Superior Court case, physicians would not certify that Bartling was terminally ill, thus he could not come under the coverage of the California Natural Death Act (6). In Bartling's case the court determined that a competent patient has common law and constitutionally based rights (both federal and Californian) to refuse treatment.

On April 26, 1986 the Supreme Court of the State of California in Bouvia $v$ Superior Court of the State of California upheld the patient's right to refuse medical treatment as a basic and fundamental right which is protected by federal and State constitutions. The court said: 'Its exercise requires no one's approval. It is not merely one vote subject to being overridden by medical opinion' (7).

The courts in both the Bartling and Bouvia cases found no practical or logical reason to limit the exercise of the right to refuse treatment to 'terminal' patients. The court held: 'The right to refuse treatment does not need the sanction or approval by any legislative act, directing how and when it shall be exercised' (8). In the same vein, referring to Elizabeth Bouvia's decision to forego medical treatment or life support through a $\vec{\circ}$ mechanical means, the court declared that the decision belonged to her. 'It is not a medical decision for her physicians to make. Neither is it a legal question whose soundness is to be resolved by lawyers or judges. It is $\overparen{\emptyset}$ not a conditional right subject to approval by ethics $\overrightarrow{\vec{A}}$ committees or courts of law. It is a moral and $i$ philosophical decision that, being a competent adult, is $\stackrel{\infty}{N}$ her's alone' (7).

The Supreme Court of California has overridden the $\stackrel{2}{?}$ provisions of that State's Natural Death Act which $\subsetneq$

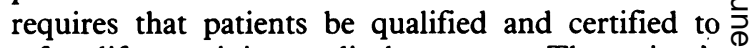
refuse life-sustaining medical treatment. The patient's $\overrightarrow{\vec{\theta}}$ right to refuse treatment or to request withdrawal of $\mathscr{\infty}^{\circ}$ treatment is not restricted to when he is certified to be terminally ill. Yet Hawaii has just passed legislation which places these very same barriers before this unqualified patient right. Under the Hawaii law, if a patient requests that treatment be withdrawn but his

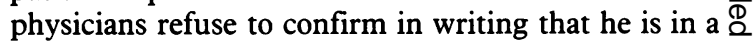
terminal condition, then he is not a certified, qualified $\overrightarrow{\vec{O}}$ patient and the status of his 'living will' is at best $\frac{}{3}$ unclear. There is no shortage of cases of this sort. Consequently, I would not be surprised if the new Hawaii statute generates litigation in Hawaii where there has been none.

In my practice as a medical ethicist I have been $\frac{0}{3}$ involved with several cases which present this very difficulty. I have frequently found myself in the 0 position of urging physicians and family members to respect the wishes of patients. The literature in medical 옹 ethics and medicine is full of discussions of cases where $>$ treatment continues in spite of the wishes of the patient; cases where the patient acknowledges and $\bar{N}$ accepts his terminal condition, but aggressive medical treatment continues.

III. The second flaw: limitation to 'terminal condition'

Many statutes defeat their intended purpose due to an effort to delineate the scope and characteristics of the class of individuals to which the law applies. The laws of Washington and Idaho are representative of most $\vec{\Phi}$ States and are useful to illustrate the problem. The $\frac{\rho}{\mathbb{Q}}$ difficulty arises out of the statutes' 'definitions' $\varrho$ together with the 'directive to physicians' and key implementing provisions. A 'qualified patient' is $\delta$ defined as 'a patient diagnosed and certified in writing을 to be afflicted with a terminal condition by two physicians, one of whom shall be the attending? 
physician, who have personally examined the patient' (8). 'Terminal condition' is defined as 'an incurable condition caused by injury, disease, or illness, which, regardless of the application of life-sustaining procedures, would, within reasonable medical judgement, produce death, and where the application of life-sustaining procedures serves only to postpone the moment of death of the patient' (8). These definitions sharply limit the class of individuals who are eligible to have their living wills followed. People involved in health care can easily imagine many individuals who would want their wishes followed but who would fail to be 'terminal' as defined above.

These definitions merit careful scrutiny since they identify the class of individuals who can execute a valid living will. In addition to the difficulty with 'qualifying and certifying' patients which has already been discussed, such requirements clearly exclude most individuals who have signed or are interested in signing living wills. It should be acknowledged that the problem is not that it is difficult to obtain certification of terminal illness as defined under the law, but rather, as defined, 'terminal illness' is utterly irrelevant to most of the cases in which a living will would actually assist in dealing with the medico-moral questions that so often arise. Terminal illness, as defined in the law, applies to those cases where the condition of the patient is so poor that 'regardless of the application of lifesustaining procedures,' death would result. In such instances one does not need a living will to shore up the decision to withhold or withdraw life-sustaining procedures! These are the cases in which the procedures are not therapeutic and thus have no medical, let alone moral, justification. So then, we have statutes that make living wills valid only in those instances where they are not needed. When a line of reasoning leads to such an absurd conclusion, ordinarily, we have reason to suspect that the position is being misrepresented. But a review of the language of the law will reveal that no such misrepresentation is present.

The Washington statute provides a model form for a 'directive to physicians' (living will). Unfortunately, the statute does not provide a section which preserves the existing common law relationship between physicians and patients as regards an individual's right to refuse or consent to medical treatment. The result is that the usual interpretation of the law is that all medical measures must be taken to save the life of the patient unless a valid living will is in place (9). Furthermore, the suggested language for the living will that is provided in the legislation is defective. The same language has been adopted by the Washington State Hospital Association and is used throughout the State.

The common interpretation of the Washington law is that life-prolonging procedures will be administered unless the patient has a valid living will which contains a paragraph that reads as follows:

'If at anytime I should have an incurable injury, disease, or illness certified to be a terminal condition by two physicians, and where the application of lifesustaining procedures would serve only to artificially prolong the moment of my death AND where my physician determines that my death is imminent WHETHER OR NOT LIFE-SUSTAINING PROCEDURES ARE UTILIZED, I direct that such procedures be withheld or withdrawn, and that $I$ be permitted to die naturally'^ (emphasis added) (9).

The difficulty here is that the law restricts the patient's right to refuse to extremely narrow circumstances. Washington's Natural Death Act, which is intended to ensure the patient's right to refuse treatment, ironically recognises such refusals only in a very limited situation, namely, when the patient is certified to be in a terminal condition by two physicians AND life-sustaining procedures would not prevent IMMINENT death (10).

Patients in Washington and most States (11) face an erosion of their right to refuse treatment, a right that has been clearly established. It certainly appears that we have legislation that has gone badly wrong. For we must either admit that key provisions of the Natural Death Act in Washington fly in the face of the long tradition of the patient's right of refusal in AngloAmerican law and run contrary to the stated objectives of the legislation, or we must find an interpretation of the law that demonstrates that it preserves the common law tradition by specifying 'one troublesome' area of patients' rights. The second alternative is untenable, rather what we have is a fundamental legislative error which has been repeated in State after State. We have botched legislation which in Washington and other States has had grave practical consequences for patients, some of whom are being treated against their wishes while others search for more hospitable hospitals.

The 'directive to physicians' which is provided by the Washington law ensures that all extraordinary measures will be taken UNLESS the above paragraph * describes the patient's condition. Most people have no difficulty imagining themselves 'not wanting everything done' in circumstances other than these! In Washington, patients who express their refusal of treatment in a broader range of circumstances would not have a valid living will. Their wishes would not be protected by the legislation, and their wishes would be respected in the State of Washington only by health care professionals who placed themselves (wittingly or otherwise) in legal jeopardy.

Legislation which invokes the restrictions of paragraph * provides legal assistance to a range of cases where none is needed. Also, it provides legislative obstacles to the range of cases where advanced directives, such as 'living wills' are needed.

There is widespread recognition that patients need support, whether legislative or legal, in a wide range of cases. A brief discussion of that range of cases, which includes both competent and incompetent patients, will be helpful. Consider the following: 
1) A competent patient requests that heroic measures not be taken, but the physician believes that those measures will serve some purpose (Bartling, Calif).

2) Incompetent patients who, when competent, appointed an agent or in writing:

a) requested that heroic measures not be taken, but the physician believes that those measures will serve some purpose (Quinlan).

b) requested that heroic measures not be taken, but family members insist that they be taken while the doctor is irresolute but acknowledges that death is not imminent with the procedures.

c) refused treatment that will prolong the dying process, (treatment without which he would die shortly, with which he would linger on for days, weeks, or months).

3) The patient who is not terminal, but is critically ill, who requested that heroic measures not be taken (treatment without which he will likely die shortly, with which he would likely recover).

All of these cases, which explicitly fail to meet the provisions of the legislation that we have been discussing, are precisely the cases in which legislation is needed to help patients have their wishes respected. Only if the patient in 1) above is strong in body and mind, has the presence to express himself clearly and repeatedly, and has the fortune to find a physician who will 'respect the patient's wishes against his medical judgement in a life and death situation'; only then, will such a patient prevail. In States without legislation the common law right to refuse treatment supports the patient's refusal. Unfortunately, in those States with legislation, such refusals have been obstructed by the formal conditions for 'qualified refusal of terminal patients'. It is not my intention here to re-open arguments for what I hold to be the well-founded right of refusal by competent patients.

No competent doctor could with justification say of a patient like Karen Ann Quinlan, while she lay in a persistent vegetative state, that ' . . . death is imminent whether or not life-sustaining procedures are utilised'. It is ironic that while cases like (2a) above played a major political role in bringing the need for natural death acts to the attention of legislatures, such patients would not qualify under the legislation that we are discussing. Surely this alone provides grounds for the view that the legislation has gone awry.

In cases such as (2b) where wishes of the now incompetent patient conflict with family members, physicians move with caution. The additional fact that the patient does not meet the condition, 'death is imminent whether or not life-sustaining procedures are utilised' serves as the decisive element in not following the patient's request. Admittedly, many physicians would adopt the defensive posture of siding with the family even without this legislation. However, the legislation virtually ensures that the patient's express wishes are not followed. Patients who fall into class $(2 c)$ may well be affected the hardest by the flawed legislation. This is most probably the largest group of patients in need of support in order to have their wishes followed and yet they are the most clearly excluded? Prior to legislation, physicians were most likely to $\overrightarrow{\mathrm{F}^{*}}$ respect the wishes of such patients, but with the legislation, they do so at the risk of violating specific provisions of the law. Namely, they would be withdrawing or withholding life-sustaining proceduresp when they have determined that the patient's death is not imminent if the life-sustaining procedures are utilised.

The problematic language of this legislation may be the result of an effort to deal with the third type of case which admittedly is morally very troublesome. However, this attempt at legislative ingenuity hașd misfired and has struck a blow against the patient's$\vec{\wedge}$ right of refusal. The courts have upheld respect foriv patient autonomy in medical decisions even where life is at stake. The courts have held that the patient's righe to refuse must be respected, not simply on religious grounds but generally, even when those wishes wilk predictably have dire consequences for the patient. The prevailing view is basically a Millian one. The exception to the autonomous will of the individual iso justified only if there is demonstrable, grievous danger to others.

The most serious problem for most natural death acts is that the living will is invoked only after the 'attending physician determines that my death is๊ imminent whether or not the artificial life-sustaining procedures are utilised' (11). What this means is tha $\overrightarrow{5}$ patients must first 'waste away' to the extent that the artificial life support systems won't work before they? can be removed. Surely this is not what the advocates? of such legislation had in mind. And surely this is not what patients who execute living wills want or expect $\widehat{D}$ One would have thought that the purpose of the living will was to implement the patient's desire not to $g \circ$. through the weeks, or months of wasting away on artificial support. The point is that artificial support is only 'support' if it is helping. This legislation onlys allows it to be removed if it is not helping. Thus, the rights of the patient who does not want this medica? treatment are either ignored or violated in Washingtorn and most States with natural death acts.

The Idaho law is striking and unique in that one can? execute a living will only after one has been diagnosed $\omega$ as having a terminal illness. One need not be omniscient in order to understand the shortcomings of this restriction. Reality is simply not so accommodating. This provision, when joined with the language of the 'directive to physicians' which is substantially the same as the Washington law discussed above, even more severely limits the relevance of the Idaho Natural Death Act.

A major virtue of the Hawaii statute is that explicitly states that it does not apply to persons who do not execute a living will. Nor does it affect the rights op patients, or those acting on their behalf to give or refuses. to give consent or withhold consent for any medica 
care! In other words, the Hawaii law explicitly affirms the common law relationship between physicians and patients, which affirms the patient's common law right to refuse any and all treatment. Unfortunately, an erosion of that relationship has generated the need for legislative support for the patient's common law right to refuse treatment.

I am led to conclude that much of the well-intended legislation in the form of 'natural death acts' actually erodes patients' rights, jeopardises health care professionals, and creates conditions that are sure to require litigation. Legislation is needed which affirms the common law relationship between patients and physicians, and which is not so narrowly drawn as to erode patients' rights, jeopardise health care professionals and generate conditions that require more rather than less litigation. Legislation which avoids the two flaws discussed at length will go a long way towards meeting these objectives.

Lawrence L Heintz PhD is Associate Professor of Philosophy at the University of Hawaii at Hilo and Medical Ethicist at Hilo Hospital.

\section{References and notes}

(1) Thirty-two of the thirty-seven statutes that I reviewed contained such a requirement. The laws reviewed were those of Alabama, Arizona, California, Colorado, Connecticut, Delaware, District of Columbia, Florida, Georgia, Idaho, Indiana, Illinois, Iowa, Kansas, Louisiana, Maine, Maryland, Mississippi, Missouri, Montana, Nevada, New Hampshire, New Mexico, North Carolina, Oklahoma, Oregon, Tennessee, Texas, Utah, Vermont, Virginia, Washington, West Virginia,
Wisconsin, and Wyoming. In addition the 'model bill' sponsored by the Society for the Right to Die contains the same language.

(2) Union Pacific Railway Co v Botsford, 141 US 250, 251 (1891).

(3) Schloendorff $v$ Society of New York Hospitals. 211 NY $125,127,129 ; 105$ NE 92, 93 (1914).

(4) Natanson v Kline. 186 Kan 393, 350 P 2d 1093 (1960), rehearing denied, $187 \mathrm{Kan} 186,354 \mathrm{P} 2 \mathrm{~d} 670$ (1060).

(5) Foster v Tourtellotte, No CV 81-5046-RMT (CD Cal Nov $16,17,(1981))$.

(6) Bartling $v$ Superior Court (Glendale Adventist Medical Center, et al, real parties in interest). 163 Cal App 3d 186 (Cal App 2d 1984).

(7) Elizabeth Bouvia v Superior Courts of the State of California for the County of Los Angeles, 1986 Los Angeles Daily fournal DAR 1318.

(8) See President's Commission for the Study of Ethical Problems in Medicine and Biomedical and Behavioral Research: Deciding to forego life-sustaining treatment 1982 Mar: 382-387.

(9) See 'No code orders guidelines' and 'No code flow chart' of Tri-State Memorial Hospital, Inc Clarkston, Washington: 1-9. See Memorandum to Hospital Administrators from Washington State Hospital Association. Legal counsel, 1-7-58: 1-13. Seattle, Washington.

(10) The case of William Bartling, California 1985, centred around these very restrictions. In that case Glendale Adventist hospital argued that the California Natural Death Act precluded removal of respiratory support because Bartling was not certified as terminally ill. The hospital prevailed in lower courts but eventually lost in the Court of Appeal after Mr Bartling was dead. Many, if not most natural death acts, are subject to interpretations which abridge the patient's legal right to control his/her own medical treatment.

(11) Twenty-six of the thirty-seven statutes that I reviewed had such language. 